\title{
Journal of Oncology Medicine \& Practice
}

\section{Teratoid Medulloepithelioma: A Rare Intraocular Tumor of a Child}

Raoudha Doghri, Lamia Charfi, Yoldez Houcine ${ }^{*}$, Nadia Boujelbene, Karima Mrad and Maha Driss

Department of Pathology, Salah Azaïz Institute, 1006 Bab Saadoun, Tunis, Tunisia

*Corresponding author: Yoldez Houcine, Department of Pathology, Salah Azaïez Institute, 1006 Bab Saadoun, Tunis, Tunisia, Tel: 0021671577850; Fax: 0021671574725; E-mail: daddoussa87@hotmail.fr

Received date: August 24, 2017; Accepted date: September 18, 2017; Published date: September 25, 2017

Copyright: ( 2017 Doghri R, et al. This is an open-access article distributed under the terms of the Creative Commons Attribution License, which permits unrestricted use, distribution, and reproduction in any medium, provided the original author and source are credited.

\begin{abstract}
Medulloepithelioma is a rare congenital neuroepithelial tumor commonly arising from the non-pigmented ciliary body epithelium and rarely from iris, retina or the optic nerve. It occurs in patient under 10 years. It is a rare neuroepithelial tumor and is the second most frequent intraocular tumour in children after retinoblastoma. Unlike cases reported in the literature in which the tumour recurs rapidly, recurrence occurred in our case five years later.
\end{abstract}

Keywords Medulloepithelioma; Childhood; Ocular tumour; Differential diagnosis; Histopathology

\section{Introduction}

Intraocular medulloepithelioma is a congenital tumor of the ciliary epithelium that typically presents during the first decade of life. The histologic diagnosis is based on characteristic ribbons of pseudo stratified neuroepithelium admixed with loose mesenchymal tissue rich in hyaluronic acid, vaguely resembling developing retina and vitreous. Malignant medulloepitheliomas consist of a proliferation of neuroblasts, which in areas can be indistinguishable from retinoblastoma. Given the rarity of medulloepithelioma, there is limited information on long-term survival. The aim of this article is to report a case of intraocular medulloepithelioma with extremely rare evolution.

\section{Case Report}

A 5-year-old girl with a history of a left eye's congenital glaucoma operated 3 years ago was complained of lack of her vision. Clinical examination found a hypervascularisation of the iris. It also revealed the presence of a nodule in the posterior portion of the globe.

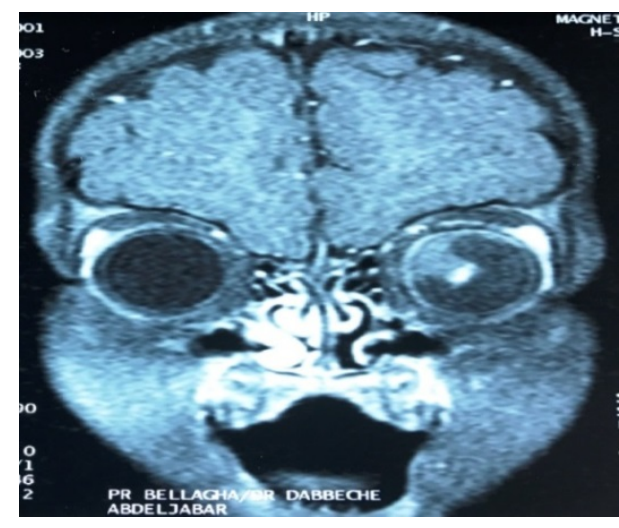

Figure 1: Well limited intra ocular tumor mass.
Standardized echo graphic examination was normal. Tomographic sections of the head and orbits confirmed the presence of a solitary intraocular tumour situated on the posterior chamber (Figure 1). The patient underwent enucleation of the left eye. The specimen was preserved in $10 \%$ formalin and submitted for histological examination. No adjuvant treatment was prescribed to the patient.

\section{Macroscopic description}

The enucleated eye measured $25 \times 25 \times 15 \mathrm{~mm}$. The eyeball was completely filled with a whitish and partially necrotic tumour that infiltrated the anterior chamber, iris and ciliary body.

\section{Microscopic description}

Sections from paraffin-embedded tissue stained with haematoxylin and eosin $(\mathrm{H} \& \mathrm{E})$ revealed in non-necrotic areas a highly cellular tumour (Figure 2).

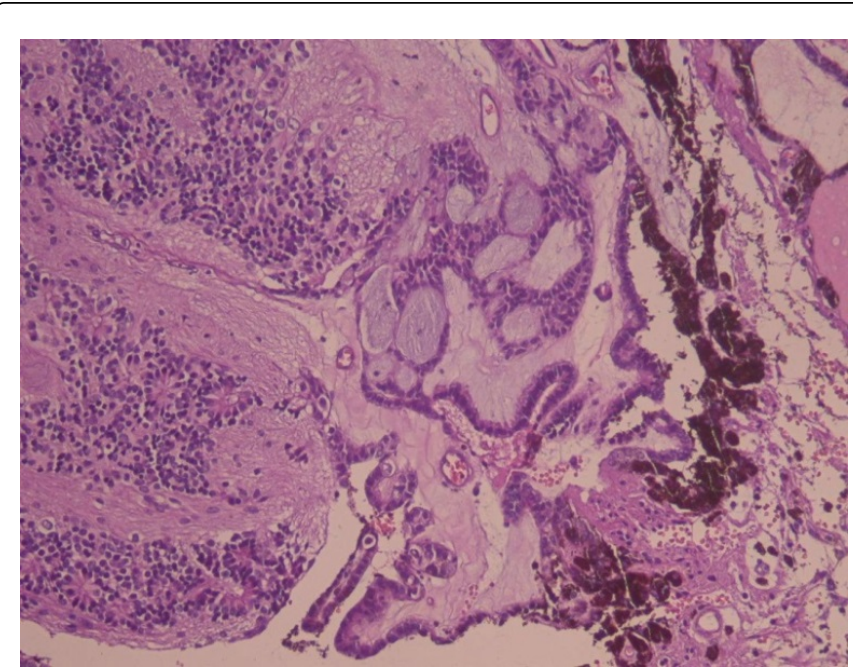

Figure 2: Tumour proliferation with increased number of cells and necrotic areas. 
The tumour cells were poorly differentiated and sometimes pigmented, with a scanty basophilic cytoplasm. Nuclear showed significant pleomorphism, mitoses and hyperchromasia. Architecture was solid, trabecular and pseudo-glandular structures alternating with cystic spaces. Differentiation into Homer-Wright and FlexnerWintersteiner-like rosettes was present (Figure 3).

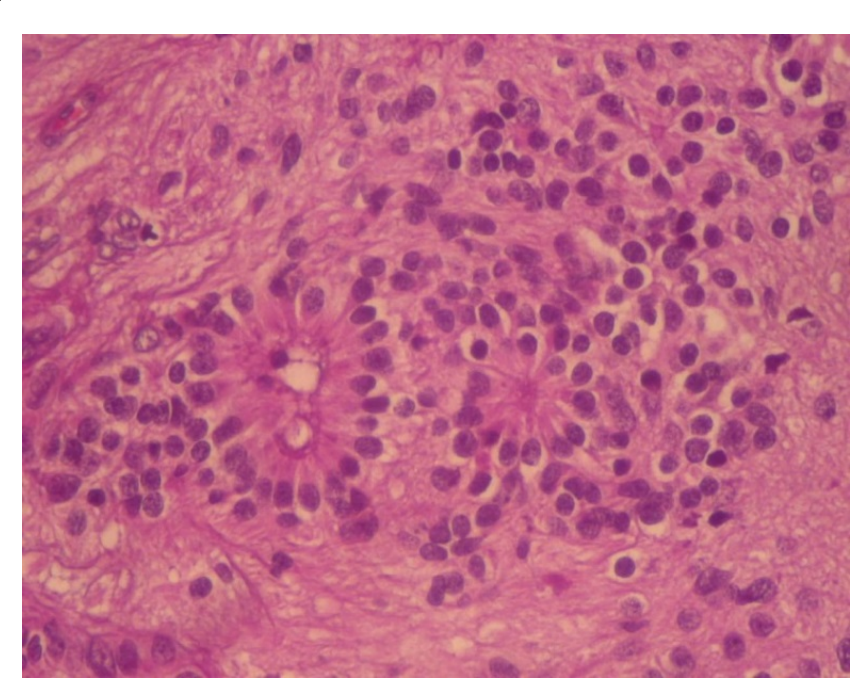

Figure 3: Differentiation into Homer-Wright and Flexner-Winter Steiner-like rosettes.

In some area, differentiation into calcified brain-like tissue (Figure 4) with fibrillary and neuroid focus was noted. The tumour didn't infiltrate the choroids or the sclera. The diagnosis of teratoid medulloepithelioma was made.

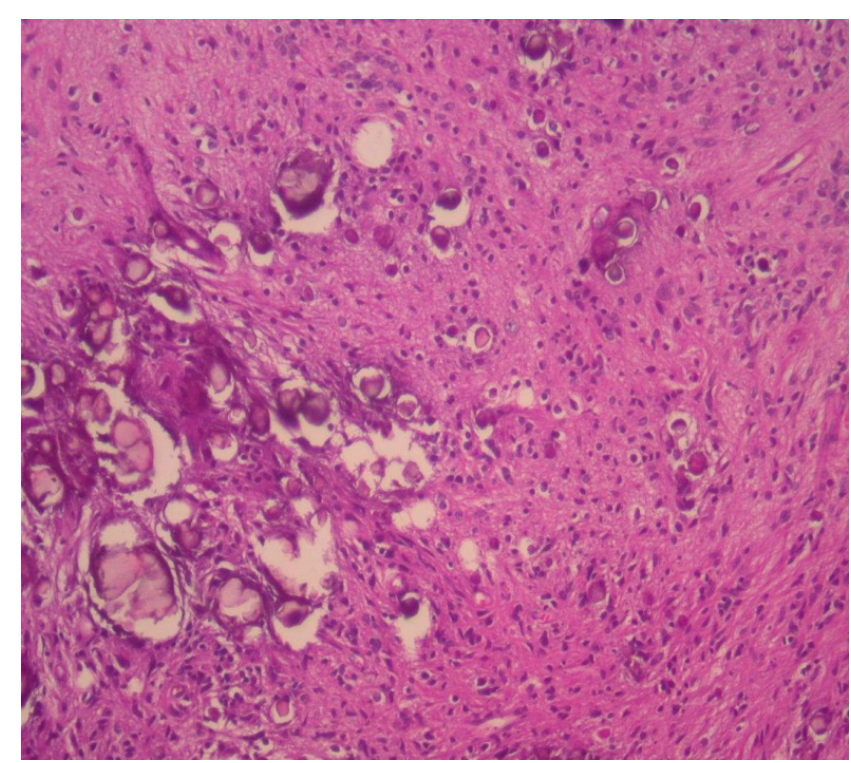

Figure 4: calcified brain-like tissue.

Five years later, despite a total enucleation, the patient was suffered from an orbital recurrence treated with local radiation therapy.

\section{Discussion}

Medulloepithelioma (ME) is a rare neuroepithelial tumour. It is the second most frequent intraocular tumour in children after retinoblastoma [1]. Medulloepithelioma arises from the medullary epithelium of the ciliary body. Occasionally, it occurs in the optic nerve $[2,3]$ and in the retinal stalk $[4,5]$. It occurs in children (middle age 5 years) without sex predilection [6]. This tumour is characterized by a slow evolution. It becomes symptomatic if it is voluminous. Clinical manifestations are blindness or decrease in visual acuity (39\%), painless (30\%), leucokoria (18\%) and mass (18\%) [1].

Related features include secondary glaucoma, iris neovascularization, cataract, lens subluxation, lens coloboma, retrolental neoplastic and cyclitic membrane [6]. Imaging techniques generally demonstrates a cyst or mass involving the ciliary body or iris. The typical echo graphical aspect is the presence of an oval or slit-like minimally reflective area in a low-to-medium reflective irregularly structured mass [7]. Zimmerman has classified medulloepithelioma as teratoid and nonteratoid types [8]. The nonteratoid medulloepithelioma (diktyoma) is a pure proliferation of cells of the medullary epithelium. teratoid medulloepithelioma, which represents $40 \%$ of all medulloepithelioma, is distinguished by the additional presence of heterologous elements, particularly cartilage, skeletal muscle, and brain tissue. It arises commonly from the non-pigmented ciliary epithelium, rarely from retina or the optic nerve [9].

Most intraocular medulloepitheliomas occur sporadically. However, cytogenetic abnormalities of DICER1 were reported in one case and association with pleuropulmonary blastoma in $5 \%$ of cases $[10,11]$.

Histologically, medulloepithelioma contain elements that closely resemble the medullary epithelium and may contain structures resembling those derived from the optic vesicle or optic cup, retinal pigmented epithelium, non-pigmented and pigmented ciliary epithelium, and vitreous [7].

In the areas of proliferating medullary epithelium, the tumor cells are characteristically arranged in cords and sheets separated by cystic spaces containing hyaluronic acid. They have considerable pleomorphism and are pleuripotential.

Structures of undifferentiated cells resembling those of retinoblastoma (Homer-Wright and Flexner-Wintersteiner-like rosettes) may be noted. However, most rosettes in these tumours have a lumen surrounded by more than a single layer of cells. Small cords of pigmented neuroepithelial cells are often present; they are usually enmeshed in non-pigmented tissue.

Malignant medulloepithelioma may not always differ appreciably from the benign tumours. The features of malignancy include the presence of undifferentiated neuroblastic cells, mitotic activity, and the presence of areas resembling soft tissue sarcoma [12]. But the most reliable criteria are invasiveness and extension outside the eye [8].

The most frequently observed heterotopic tissue is hyaline cartilage. Brain-like tissue and skeletal muscle may also be noted.

The histologic differential diagnosis of medulloepithelioma is broad, ranging from retinoblastoma and sarcoma to ocular teratoma, ciliary epithelial adenoma and adenocarcinoma [6-8]. Medulloepithelioma is the only ocular childhood neoplasm that can histologically mimic retinoblastoma and constitute a diagnostic problem for the pathologist. 
Page 3 of 3

Enucleation is generally recommended because local resection is insufficient and the recurrent rate is high. The role of radiotherapy and chemotherapy are unknown.

The prognosis for medulloepithelioma limited to the eye is good because of the slow growth rate, and rare lymphatic and haematogenous dissemination [7].

In a series of 41 patients with ciliary body ME, systemic metastasis occurred in 3 cases (8\%) over a mean follow-up of 49 months, all of whom presented with extra scleral extension of tumor due to mean delay in diagnosis by 39 months [6]. Distant metastases to the lymph nodes, parotid glands, lungs and mediastinum have been described. Follow-up on the 56 patients reported by Broughton and Zimmerman showed tumour-related deaths in 4 (12\%) occurred in patients with malignant tumours with extra ocular extension detected on histopathological examination [8]. Deaths were preceded in three cases by orbital recurrence; 3 patients died with intracranial extension and the fourth with distant metastasis. Of the original 56 tumours 37 were judged histologically malignant and 10 had extra-ocular spread. Unlike cases reported in the literature in which the tumour recurs rapidly, recurrence occurred in our case five years later. Although the roles of radiotherapy and chemotherapy are not well evaluated, a good response to radiotherapy was achieved.

The major predictor of death was extra ocular extension [13]. The value of radiation therapy and chemotherapy with extra ocular spread was too limited to draw meaningful conclusions $[8,13]$.

\section{Conclusion}

In summary, because of the rarity of medulloepithelioma in adults, only little information concerning its clinical evolution is available. Nevertheless this tumour should be taken into consideration in the differential diagnosis of retinoblastoma. Although, it is known recur in a very brief delay, recurrence occurred in our case five years later.

\section{References}

1. Mojgan D (2014) Medulloepithelioma of the ciliary body. Bulletin of the French Division of the AIP 60: 159-164

2. Reese AB (1957) Medulloepithelioma (dictyoma) of the optic nerve. Am J Ophthalmol 44: 4-6.

3. Green WR, Iliff WJ, Trotter RR (1974) Malignant teratoid medulloepithelioma of the optic nerve. Arch Ophthalmol 91: 451.

4. Anderson SR (1962) Medulloepithelioma of the retina. Int Ophthalmol Clin 2: 483-506.

5. Mullaney J (1974) Primary malignant medulloepithelioma of the retinal stalk. Am J Ophthalmol 77: 499-504.

6. Saunders T, Margo CE (2012) Intraocular medulloepithelioma. Arch Pathol Lab Med. 136: 212-216.

7. Lloyd III WC, O’Hara M (2001) Malignant teratoid medulloepithelioma: Clinical-echographic-histopathologic correlation. J AAPOS 5: 395-397.

8. Zimmerman LE (1970) The remarkable polymorphism of tumors of the ciliary epithelium. The Norman McAlister Gregg Lecture. Part 1. Trans Austr Coli Ophthalmol 2: 114-125.

9. Andersen S (1971) Differentiation features in some retina tumor and in dysplastic retinal conditions. Am J Ophtalmol 1: 231-241

10. Kramer GD, Arepalli S, Shields CL, Shield JA (2014) Ciliary body medulloepithelioma association with pleuropulmonary blastoma in familial tumour predisposition syndrome. J Pediatr Ophtalmol Strabismus 51: e48-50.

11. Priest JR, Williams GM, Manera R, Jekinson H, Brûndler MA, et al (2011) Ciliary body medulloepithelioma: Four cases associated with pleuropulmonary blastoma: A report from the International pleuropulmonary blastoma registry. Br J OPhtalmol 95: 1001-1005.

12. Yanko L, Behar A (1978) Teratoid intraocular medulloepithelioma. Am J Ophtalmol 85: 850-853.

13. Timothy S, Curtis EM (2012) Intraocular medulloepithelioma. Arch Pathol Lab Med 136: 216-212. 